\title{
Multidetector CT angiography of the Circle of Willis: association of its variants with carotid artery disease and brain ischemia
}

\author{
Andrea Varga ${ }^{1}$ (1) Giovanni Di Leo ${ }^{2} \cdot$ Péter Vince Banga $^{3} \cdot$ Csaba Csobay-Novák $^{3,4} \cdot$ Márton Kolossváry $^{5}$. \\ Pál Maurovich-Horvat ${ }^{5} \cdot$ Kálmán Hüttl ${ }^{3,4}$
}

Received: 29 December 2017 / Revised: 17 May 2018 / Accepted: 29 May 2018 / Published online: 19 June 2018

(C) The Author(s) 2018

\begin{abstract}
Purpose (1) to estimate the prevalence of Circle of Willis (CoW) variants in patients undergoing carotid endarterectomy, (2) to correlate these variants to controls and (3) cerebral ischemia depicted by computed tomography (CT).

Materials and methods After Institutional Review Board approval, data of 544 carotid endarterectomy patients (331 males, mean

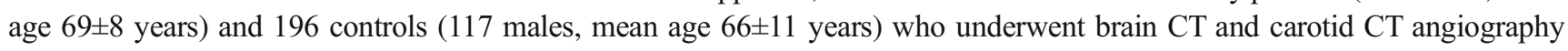
(CTA) were retrospectively analysed. Two observers independently classified each CoW segment as normal, hypoplastic (diameter $<0.8 \mathrm{~mm}$ ) or non-visualized. Four groups of CoW variants based on the number of hypoplastic/non-visualized segments were correlated with clinical data (ANOVA, $\chi^{2}$ and multivariate logistic regression analysis). Intra- and inter-observer agreement was estimated using Cohen $\mathrm{K}$ statistics.

Results High prevalence of CoW variants (97\%) and compromised CoW (81\%) was observed in the study group and significant difference was found in the distribution of CoW variants compared to controls $(p<0.001)$, internal carotid artery (ICA) stenosis being the only independent predictor of CoW morphology $(p<0.001)$. Significant correlation was found between CoW configuration and brain ischemia in the study group $(p=0.002$ ). ICA stenosis of $\geq 90 \%$ was associated to higher rate of ipsilateral A1 hypoplasia/non-visualization $(p<0.001)$. Intra- and inter-observer agreement was from substantial to almost perfect (Cohen $\mathrm{K}=0.75-1.0$ ).

Conclusion Highly variable CoW morphology was demonstrated in patients undergoing endarterectomy compared to controls. Likely compromised $\mathrm{CoW}$ in relation to cerebral ischemia was observed in a large cohort of carotid endarterectomy subjects.

\section{Key points}

- CoW variant distribution significantly differed in the study and control groups $(p<0.001)$.

- ICA stenosis was the only independent predictor of CoW morphology $(p<0.001)$.

- Severely compromised CoW configuration showed significant association with brain ischemia ( $p=0.002)$.
\end{abstract}

Keywords Circle of Willis · Anatomy · Carotid Artery, Internal · CT Angiography · Endarterectomy, Carotid

Andrea Varga

varga.andrea.bandi@gmail.com

1 Department of Diagnostic Radiology, Heart and Vascular Center, Semmelweis University, 18 Határör street, Budapest 1122, Hungary

2 Radiology Unit, IRCCS Policlinico San Donato, Milan, Italy

3 Department of Vascular Surgery, Heart and Vascular Center, Semmelweis University, Budapest, Hungary

4 Department of Interventional Radiology, Heart and Vascular Center, Semmelweis University, Budapest, Hungary

5 MTA-SE Cardiovascular Imaging Research Group, Heart and Vascular Center, Semmelweis University, Budapest, Hungary

$\begin{array}{ll}\begin{array}{ll}\text { Abbreviations } \\ \text { 3D TOF MRA }\end{array} & \begin{array}{l}\text { 3D time-of-flight MRA } \\ \text { Precommunicating segment } \\ \text { of the anterior cerebral artery }\end{array} \\ \text { AComA } & \text { Anterior communicating artery } \\ \text { CoW } & \text { Circle of Willis } \\ \text { CTA } & \text { Computed tomography angiography } \\ \text { DSA } & \text { Digital subtraction angiography } \\ \text { ICA } & \text { Internal carotid artery } \\ \text { MRA } & \text { Magnetic resonance angiography } \\ \text { P1 } & \begin{array}{l}\text { Precommunicating segment of } \\ \text { the posterior cerebral artery }\end{array} \\ \text { PComA } & \text { Posterior communicating artery } \\ \text { TIA } & \text { Transient ischemic attack }\end{array}$

\section{Abbreviations}

3D TOF MRA
3D time-of-flight MRA of the anterior cerebral artery Anterior communicating artery Computed tomography angiography Digital subtraction angiography nternal carotid artery Precommunicating segment of the posterior cerebral artery Transient ischemic attack 


\section{Introduction}

Reduction of blood flow due to severe internal carotid artery (ICA) stenosis requires compensation to maintain sufficient perfusion of the affected vascular territory. The Circle of Willis (CoW) is considered the primary collateral pathway, which may allow blood supply from the contralateral ICA or from the basilar artery $[1,2]$, depending on the continuity of the anterior and posterior parts of the CoW.

In autopsy studies the prevalence of absent or hypoplastic segments was increased in stroke patients as compared to normal subjects $[3,4]$. Some investigators reported that incomplete collateral pathways in symptomatic ICA stenosis were associated with increased risk of infarction $[1,5]$. An imaging study showed less CoW variants in strongly selected patients with transient ischemic attack (TIA) or ischemic stroke due to carotid artery disease [6], while other authors found higher prevalence of hypoplastic or non-visualized segments [7-9]. Furthermore, patients who have collaterals supplying the operative side are less prone to perioperative stroke [1] or cerebral ischemia during clamping of the ICA [10-13].

Several articles addressed the CoW anatomy using digital subtraction angiography (DSA) [1], transcranial Doppler ultrasound $[5,14]$ and 3D time-of-flight (3D TOF) magnetic resonance angiography (MRA) [6, 9-12, 14-23]. However, few reports have been published with multi-detector computed tomography angiography (CTA) [7, 24-29], only one of them focusing on patients with ICA stenosis and comparing them with controls [7].

CTA is a fast, minimally invasive examination with high spatial resolution. It is increasingly used for the preoperative assessment of steno-occlusive carotid disease, providing detailed anatomical depiction of the extracranial and intracranial arteries with a single scan. As data on the CoW variants in carotid artery disease are sparse and conflicting, we aimed to estimate the prevalence of $\mathrm{CoW}$ variants in a cohort of 544 carotid endarterectomy patients compared to control subjects and correlate these variants with cerebral ischemia. We hypothesized an association between compromised CoW and ICA stenosis as well as higher likelihood of cerebral infarcts.

\section{Materials and methods}

\section{Study group}

After Institutional Review Board approval, we retrospectively analysed all brain CT and carotid CTA examinations of patients who (1) underwent carotid endarterectomy in our hospital between January 2013 and November 2015 for $>70 \%$ symptomatic or $>80 \%$ asymptomatic ICA stenosis, according to the NASCET criteria [30]; and (2) had adequate CT and CTA to evaluate the CoW. Procedures were in accordance with institutional guidelines. To avoid biases, no patient selection was made.

\section{Control group}

Reviewing carotid CTAs performed in our institution from January 2014 to November 2017, we identified all subjects with either negative CTA or minor/mild carotid atherosclerosis to provide a sex-matched control group.

\section{Brain CT and CTA examinations}

All examinations were performed using a 256-slice scanner (Brilliance iCT 256, Philips Healthcare, Best, The Netherlands).

Brain CT was obtained using the following parameters (field of view $200-250 \mathrm{~mm}$, collimation $64 \times 0.625$, pitch 0.39 , gantry rotation time $400 \mathrm{~ms}$, tube voltage $120 \mathrm{kVp}$, tube current 120-204 mAs, slice thickness $2 \mathrm{~mm}$, dose-length product 312-626 mGycm).

All CTA examinations were performed from the aortic arch to under the vertex using the following parameters (field of view $180-200 \mathrm{~mm}$, collimation $128 \times 0.625$, pitch 0.758 , gantry rotation time $330 \mathrm{~ms}$, tube voltage $120 \mathrm{kVp}$, tube current 76-206 mAs, dose-length product 220-608 mGycm). Bolus tracking technique in the aortic arch was used with $50 \mathrm{ml}$ of iodinated contrast agent (Iomeron 400, Bracco Imaging SpA, Milan, Italy) followed by $40 \mathrm{ml}$ saline bolus, both injected at 5 $\mathrm{ml} / \mathrm{s}$ through a $18 \mathrm{G}$ cannula. Contiguous sections were reconstructed with $0.67-\mathrm{mm}$ slice thickness and $512 \times 512$ matrix using hybrid iterative reconstruction technique (iDOSE, Philips Healthcare, Cleveland, OH, USA).

Images were evaluated on a dedicated workstation (IntelliSpace Portal, Philips Healthcare, Best, The Netherlands). Visualization included 3-mm maximum intensity projection slabs parallel and perpendicular to the anterior skull base, providing an overview of the $\mathrm{CoW}$, but final decisions were made on the thin section images.

\section{Study group brain CT assessment}

The presence of any ICA territory infarct at the side of surgery was classified as a positive CT regardless of the infarct's nature (acute/subacute/chronic or territorial/lacunar/watershed). Conversely, the lack of any detectable infarct in the corresponding ICA territory was regarded as a negative CT result.

\section{Assessment of the supra-aortic arteries and the CoW}

In the study group for each side, ICA stenosis was determined according to the NASCET method [30] and categorized using the following four-point score: 0 when $<70 \%, 1$ when 70 $89 \%, 2$ when $90-99 \%$, and 3 when occluded. The score of the two sides were summed up (range 0-6). 
The CoW was evaluated according to three different approaches both in the study and control groups, as follows:

1. Each individual segment was scored as normal (diameter $\geq 0.8 \mathrm{~mm}$ ), hypoplastic ( $<0.8 \mathrm{~mm}$ ) or non-visualized. Each hypoplasia or non-visualization was than classified as single variant or combined with other variants of the CoW. We considered the AcomA as patent if the junctions of A1 and A2 segments were in close contact and, therefore, not separable from each other on the CTA. The communication of the PcomA with both the ICA and the posterior cerebral artery had to be visualized for defining the PcomA;

2. The anterior and two posterior parts of the CoW were considered separately. For the anterior part, both A1 segments and AComA were evaluated, since all vessels should be sufficiently developed to allow collateral supply from the contralateral to the ipsilateral ICA. For the posterior part, the P1 segment and the PComA were assessed on each side. Data on the anterior and posterior parts were crossed in a contingency table showing all observed combinations of the $\mathrm{CoW}$ (mirror configurations were not considered as separate entities). Moreover, the anterior and the two posterior parts were classified as complete (all segments normal), hypoplastic (any of the components hypoplastic) or incomplete (any of the segments non-visualized);

3. Four reclassified groups based on the number of hypoplastic and non-visualized segments were defined, as follows I) complete CoW or only one hypoplastic segment (not/minimally compromised CoW); II) $\geq 2$ hypoplastic segments; III) one non-visualized segment; IV) $\geq 2$ nonvisualized segments (severely compromised CoW). Groups II), III) and IV) together were defined as "compromised CoW".

\section{Reproducibility of CTA}

To estimate the inter-observer agreement in defining CoW morphology on CTA, each individual study subject was assessed by two independent radiologists (R1 with 13 years of experience in vascular imaging; R2, with 8 years of experience), unaware of patient characteristics. In case of discrepancy, agreement was reached by consensus. Intra-observer agreement was evaluated for both observers by comparing data of 100 randomly selected patients at two different reading sessions at least 2 months apart.

\section{Statistical analysis}

Continuous variables were expressed as mean \pm standard deviation (SD), while categorical variables as counts and percentages. Distributions were given according to the three different approaches to classify the CoW; moreover, variants of the anterior part of the CoW were crossed with those of the posterior part. Bivariate association analysis was performed using the ANOVA for continuous variables or using the $\chi^{2}$ test for categorical variables. The multiplicity of statistical tests accounts for applying the Bonferroni method. Considering that a statistical test was performed for each of the 11 analysed variables, the threshold for significance was divided by 10 and defined as $p \leq 0.005$. All variables that were significantly different between study patients and controls at bivariate analysis were entered into a multivariate logistic regression analysis for ordinal data.

In the $\chi^{2}$ test used for brain CT analysis $p \leq 0.05$ was considered statistically significant.

Intra- and inter-observer agreement was estimated using the Cohen $\mathrm{k}$ statistics. Cohen's $\mathrm{K}$ values were interpreted as: 0.81-1.00, excellent; 0.61-0.80, good.

All statistical calculations were performed using SPSS software (SPSS v.23; IBM Corp., Armonk, NY).

\section{Results}

\section{Characteristics of the study and control groups}

From 898 consecutive carotid endarterectomy patients in the study period, we excluded 354 patients $(39 \%)$ due to poor image quality $(24 / 898,3 \%)$ or missing/incomplete CTA $(330 / 898,36 \%)$. The remaining 544 study subjects were analysed (331 males, mean age $69 \pm 8$ years, range $44-90$ years). Of them, 205 (38\%) had symptomatic ICA stenosis, including 59 patients $(11 \%)$ with previous minor stroke, 25 (5\%) with amaurosis fugax and $121(22 \%)$ with TIA. The three study subjects with stenosis of $<70 \%$ were all symptomatic.

A total of 196 control subjects were analysed (117 males, mean age $66 \pm 11$ years, range $37-93$ years). The indication for CTAs was: (1) false positive ultrasound scan in 58 cases (30\%); (2) brachiocephalic/subclavian artery stenosis or aneurysm in 27 (14\%); (3) cardiology referral in 29 (14.5\%); (4) diagnostic work-up before vascular intervention/surgery in 15 (7.5\%); (5) neurology referral in $56(29 \%)$; (6) carotid artery dissection in five $(2 \%)$; $(7)$ neck tumor in four $(2 \%)$; and $(8)$ vascular malformation in two (1\%).

Further details are reported in Table 1.

\section{Study group analysis}

Brain CT analysis At CT 146/544 study subjects (27\%) had a detectable recent or old infarct in the territory of the operated ICA. As shown by the $\chi^{2}$ test, the prevalence of brain ischemia was significantly higher $(p=0.002)$ in subjects with 
Table 1 Demographics, cardiovascular risk factors, degree of internal carotid artery stenosis and different configurations of Circle of Willis in 544 study subjects and 196 control subjects

\begin{tabular}{|c|c|c|c|}
\hline & $\begin{array}{l}\text { Study group } \\
(N=544)\end{array}$ & $\begin{array}{l}\text { Control group } \\
(N=196)\end{array}$ & $p$-value \\
\hline \multicolumn{4}{|l|}{ Demographics } \\
\hline Male gender & $331(61 \%)$ & $117(60 \%)$ & 0.777 \\
\hline Mean age \pm SD (years) & $69 \pm 8$ & $66 \pm 11$ & $<0.001$ \\
\hline Symptomatic & $205(38 \%)$ & - & - \\
\hline Cardiovascular risk factors, $N(\%)$ & & Data available in & \\
\hline Hypertension & $500(92 \%)$ & $110(64 \%)$ & $<0.001$ \\
\hline Cigarette smoking & $175(32 \%)$ & $16(9 \%)$ & $<0.001$ \\
\hline Hyperlipidemia & $234(43 \%)$ & $49(28 \%)$ & 0.001 \\
\hline Coronary artery disease & $170(31 \%)$ & $30(17 \%)$ & $<0.001$ \\
\hline Chronic pulmonary disease & $53(10 \%)$ & $13(8 \%)$ & 0.377 \\
\hline Chronic kidney disease (Stage IIIb-V) & $16(3 \%)$ & $6(3 \%)$ & 0.726 \\
\hline Diabetes & $203(37 \%)$ & $32(18 \%)$ & $<0.001$ \\
\hline \multicolumn{4}{|l|}{ Carotid artery stenosis, $N(\%)$} \\
\hline$<70 \%$ on both sides (Score 0 ) & $3(0.6 \%)$ & - & - \\
\hline $70-89 \%$ on the side of surgery (Score 1) & $128(23.5 \%)$ & - & - \\
\hline $70-89 \%$ on both sides (Score 2 ) & $26(4.8 \%)$ & - & - \\
\hline $90-99 \%$ on the side of surgery (Score 2 ) & $282(51.7 \%)$ & - & - \\
\hline $\begin{array}{l}90-99 \% \text { on the side of surgery }+70-89 \% \\
\text { on the contralateral side (Score 3) }\end{array}$ & $54(9.9 \%)$ & - & - \\
\hline 90-99\% on both sides (Score 4) or & $51(9.4 \%)$ & - & - \\
\hline \multirow{2}{*}{\multicolumn{4}{|c|}{$\begin{array}{l}70-89 \% \text { on the side of surgery }+ \\
\text { contralateral occlusion (Score } 4 \text { ) or } \\
90-99 \% \text { on the side of surgery }+ \\
\text { contralateral occlusion (Score 5) }\end{array}$}} \\
\hline & & & \\
\hline \multicolumn{4}{|l|}{ CoW groups $N(\%)$} \\
\hline Group I) & $78(14 \%)$ & $55(28 \%)$ & \multirow[t]{4}{*}{$<0.001$} \\
\hline Group II) & $97(18 \%)$ & $52(27 \%)$ & \\
\hline Group III) & $191(35 \%)$ & $55(28 \%)$ & \\
\hline Group IV) & $178(33 \%)$ & $34(17 \%)$ & \\
\hline
\end{tabular}

CoW $=$ Circle of Willis; $S D=$ standard deviation

severely compromised CoW (35\%) as compared to the pooled groups I)-III) (23\%). Table 2. As a recent brain infarct larger than $1 / 3$ of the corresponding ICA territory is a contraindication for carotid endarterectomy, we have not found major recent infarction in any of our study patients.

Analysis of all individual segments The number and frequency of normal, hypoplastic or non-visualized segments (single variant or mostly combined with others) are presented in Table 3. Non-visualized PComA (447/ 1088, 41.1\%), AComA hypoplasia $(154 / 544,28.3 \%)$ and PComA hypoplasia $(275 / 1088,25.3 \%)$ were the most frequent.

The frequencies of non-visualization and hypoplasia of each CoW segment reported in anatomic and imaging studies as well as those found by us are summarized in Table 4 .

Analysis of the anterior, posterior parts and the entirety of the CoW The frequency and number of all possible combinations of the anterior and posterior variants are listed in Table 5. The variants of the anterior part fell into five types. The posterior part of the CoW demonstrated higher variability and was classified into 16 groups. Bilateral non-visualization of the PComA (118/544, 21.7\%), combined non-visualization of one PComA and hypoplasia of the other PcomA (93/544, 17.1\%) were the most frequent.

Only 19/544 study subjects had an entirely complete CoW $(3.5 \%)$.

Examples of $\mathrm{CoW}$ groups I)-IV) are shown in Figs. $1,2,3$, and 4 .

Correlation analysis The association of CoW configurations and demographics, cardiovascular risk factors, and degree of ICA stenosis is detailed in Table 2. Groups II), III) and IV) together represented $81 \%(443 / 544)$ of our study group.

After Bonferroni correction, the association of CoW configuration and ICA stenosis did not reach the pre-specified significance level $(p=0.010)$. Unilateral stenosis of $90-99 \%$ (Score 2) was the most frequent in all the four CoW configurations, ranging from $44 \%$ to $61 \%$. Notably, high carotid stenosis scores (Scores 4 and 5) were the least frequent in group IV). Considering each single CoW segment, ICA stenosis of the side of surgery was correlated only to ipsilateral A1 segment $(p<0.001)$. Hypoplastic/non-visualized ipsilateral A1 segment was present in $81 / 370$ (22\%) of patients with an ICA stenosis of $\geq 90 \%$ while only in $14 / 174$ (8\%) of patients with a stenosis of $<90 \%$. 
Table 2 Demographics, cardiovascular risk factors, degree of internal carotid artery stenosis and percentage of cerebral ischemia in different configurations of Circle of Willis in 544 study subjects

\begin{tabular}{|c|c|c|c|c|c|}
\hline & $\begin{array}{l}\text { Group I) } \\
\text { Complete CoW or } \\
1 \text { hypoplastic segment }\end{array}$ & $\begin{array}{l}\text { Group II) } \\
\geq 2 \text { hypoplastic } \\
\text { segments }\end{array}$ & $\begin{array}{l}\text { Group III) } \\
1 \text { non-visualized } \\
\text { segment }\end{array}$ & $\begin{array}{l}\text { Group IV) } \\
\geq 2 \text { non-visualized } \\
\text { segments }\end{array}$ & $p$-value \\
\hline Demographics & $(n=78)$ & $(n=97)$ & $(n=191)$ & $(n=178)$ & \\
\hline Male gender & $48(61.5 \%)$ & $51(52.6 \%)$ & $121(63.4 \%)$ & $111(62.4 \%)$ & 0.324 \\
\hline Age $\pm \mathrm{SD}$ (years) & $68 \pm 9$ & $67 \pm 8$ & $69 \pm 8$ & $70 \pm 8$ & 0.107 \\
\hline Symptomatic & $21(26.9 \%)$ & $38(39.2 \%)$ & $68(35.6 \%)$ & $78(43.8 \%)$ & 0.067 \\
\hline \multicolumn{6}{|l|}{ Cardiovascular risk factors, $N(\%)$} \\
\hline Hypertension & $70(89.7 \%)$ & $89(91.8 \%)$ & $175(91.6 \%)$ & $166(93.2 \%)$ & 0.813 \\
\hline Cigarette smoking & $26(33.3 \%)$ & $39(40.2 \%)$ & $73(38.2 \%)$ & $37(20.8 \%)$ & 0.001 \\
\hline Hyperlipidemia & $41(47.5 \%)$ & $41(42.3 \%)$ & $77(40.3 \%)$ & $75(43.9 \%)$ & 0.315 \\
\hline Coronary artery disease & $34(43.6 \%)$ & $31(32.0 \%)$ & $52(27.2 \%)$ & $53(29.8 \%)$ & 0.067 \\
\hline Chronic pulmonary disease & $9(8.9 \%)$ & $14(14.4 \%)$ & $19(9.9 \%)$ & $11(7.1 \%)$ & 0.290 \\
\hline Chronic kidney disease (Stage IIIb to V) & $2(2.0 \%)$ & $5(5.2 \%)$ & $4(2.1 \%)$ & $5(3.2 \%)$ & 0.472 \\
\hline Diabetes & $26(31.7 \%)$ & $36(37.1 \%)$ & $69(36.1 \%)$ & $72(42.3 \%)$ & 0.707 \\
\hline \multicolumn{6}{|l|}{ ICA stenosis, $N(\%)$} \\
\hline$<70 \%$ on both sides (Score 0$)$ & $0(1.0 \%)$ & $0(0.0 \%)$ & $0(0.0 \%)$ & $3(1.3 \%)$ & 0.010 \\
\hline $70-89 \%$ on the side of surgery (Score 1 ) & $13(20.8 \%)$ & $20(20.6 \%)$ & $52(27.2 \%)$ & $43(22.6 \%)$ & \\
\hline $70-89 \%$ on both sides (Score 2 ) & $5(5.9 \%)$ & $3(3.1 \%)$ & $8(4.2 \%)$ & $10(5.8 \%)$ & \\
\hline $90-99 \%$ on the side of surgery (Score 2) & $35(43.6 \%)$ & $59(60.8 \%)$ & $94(49.2 \%)$ & $94(54.8 \%)$ & \\
\hline $\begin{array}{l}90-99 \% \text { on the side of surgery }+ \\
70-89 \% \text { on the contralateral side (Score } 3)\end{array}$ & $12(13.9 \%)$ & $5(5.2 \%)$ & $14(7.3 \%)$ & $23(13.5 \%)$ & \\
\hline $\begin{array}{l}90-99 \% \text { on both sides (Score } 4 \text { ) or } \\
70-89 \% \text { on the side of surgery }+ \\
\text { contralateral occlusion (Score } 4 \text { ) or } \\
90-99 \% \text { on the side of surgery }+ \\
\text { contralateral occlusion (Score 5) }\end{array}$ & $13(14.9 \%)$ & $10(10.3 \%)$ & $23(12.0 \%)$ & $5(1.9 \%)$ & \\
\hline \multicolumn{6}{|l|}{ Brain CT N (\%) } \\
\hline Negative $398(73 \%)$ & $61(15 \%)$ & $74(19 \%)$ & $151(38 \%)$ & $112(28 \%)$ & $0.002 *$ \\
\hline Positive $146(27 \%)$ & $19(13 \%)$ & $24(16 \%)$ & $42(29 \%)$ & $61(42 \%)$ & \\
\hline
\end{tabular}

$S D=$ standard deviation; $I C A=$ internal carotid artery

${ }^{*} \chi^{2}$ test between pooled Groups I-III versus Group IV

The percentage of smokers was the lowest in patients with severely compromised CoW. The other comparisons showed no significant difference.

Reproducibility of the CTA The inter-observer agreement in the assessment of the AComA was good $(\kappa=0.75)$ while all other $K$ values were excellent (intra-observer agreement $\kappa=0.84-1.0$; inter-observer agreement $\kappa=0.82-$ 0.92).

We evaluated $3808(544 \times 7)$ segments and encountered inter-observer discrepancy in 212 cases (5.6\%), mostly for the PcomA (98/212, 46.2\%), followed by the AComA (60/ $21228.3 \%$ ). These were mainly one-category discrepancies (hypoplasia versus normal/non-visualization) in 196/212 $(92.5 \%)$.

\section{Control group analysis}

Analysis of all individual segments Hypoplasia of PComA (121/392, 30.9\%), non-visualization of PComA (110/392, $28.0 \%$ ) and hypoplasia of AComA (40/196, 20.4\%) were the most frequent variants in control subjects (Table 3 ).
Non-visualization of the A1 and AComA was rare, 4/392 $(1.0 \%)$ and $1 / 196(0.5 \%)$, respectively.

Analysis of the anterior, posterior parts and the entirety of the CoW Amongst controls, the most common posterior variants were unilateral PComA hypoplasia (43/196, 21.9\%), bilateral PComA hypoplasia $(41 / 196,20.9 \%)$, bilateral nonvisualization of the PComA $(31 / 196,15.8 \%)$, combined non-visualization of one PComA and hypoplasia of the other PcomA $(29 / 196,14.8 \%)$ and unilateral non-visualization of PComA (24/196, 12.2\%). CoW.

Of 196 control subjects, $21(11 \%)$ had an entirely complete

\section{Comparison of the study and control groups}

At bivariate analysis (Table 1), the study subjects and controls were different in terms of five cardiovascular risk factors as well as in terms of coronary artery disease $(p<0.001$ for all). Moreover, they differed in CoW variant distribution $(p<0.001)$. However, the multivariate logistic regression analysis showed that the ICA stenosis was the only independent predictor of CoW morphology $(p<0.001)$. Not or minimally 
Table 3 Number and frequency of normal, hypoplastic or non-visualized/incomplete individual segments and anterior and posterior parts of the Circle of Willis of 544 study subjects and 196 control subjects

\begin{tabular}{|c|c|c|c|c|c|c|c|c|}
\hline \multirow[t]{2}{*}{ Segment/Circle } & & \multicolumn{3}{|c|}{ STUDY GROUP $(N=544)$} & \multicolumn{3}{|c|}{ CONTROL GROUP $(N=196)$} & \multirow[t]{2}{*}{$p^{*}$} \\
\hline & & Normal & Hypoplasia & Non-visualization & Normal & Hypoplasia & Non-visualization & \\
\hline \multirow[t]{3}{*}{$\operatorname{AComA}(\mathbf{N})$} & All & $369(67.8 \%)$ & $154(28.3 \%)$ & $21(3.9 \%)$ & $155(79.1 \%)$ & $40(20.4 \%)$ & $1(0.5 \%)$ & 0.003 \\
\hline & Single variant & N/A & $9(1.7 \%)$ & $2(0.4 \%)$ & & & & \\
\hline & Combined variant & $\mathrm{N} / \mathrm{A}$ & $145(26.7 \%)$ & $19(3.5 \%)$ & & & & \\
\hline \multirow{3}{*}{$\begin{array}{l}A 1 \\
(N \times 2)\end{array}$} & All & $964(88.6 \%)$ & $81(7.4 \%)$ & $43(4.0 \%)$ & $380(97.0 \%)$ & $8(2.0 \%)$ & $4(1.0 \%)$ & $<0.001$ \\
\hline & Single variant & $\mathrm{N} / \mathrm{A}$ & $6(0.6 \%)$ & $2(0.2 \%)$ & & & & \\
\hline & Combined variant & N/A & $75(6.9 \%)$ & $41(3.8 \%)$ & & & & \\
\hline \multirow{3}{*}{$\begin{array}{l}\operatorname{PComA} \\
(\mathbf{N} \times 2)\end{array}$} & All & $366(33.6 \%)$ & $275(25.3 \%)$ & $447(41.1 \%)$ & $161(41.1 \%)$ & $121(30.9 \%)$ & $110(28.0 \%)$ & 0.008 \\
\hline & Single variant & $\mathrm{N} / \mathrm{A}$ & $36(3.3 \%)$ & $26(2.4 \%)$ & & & & \\
\hline & Combined variant & N/A & $239(22.0 \%)$ & $421(38.7 \%)$ & & & & \\
\hline \multirow{3}{*}{$\begin{array}{l}\mathbf{P 1} \\
(\mathrm{N} \times 2)\end{array}$} & All & $948(87.1 \%)$ & $81(7.4 \%)$ & $59(5.4 \%)$ & $354(90.3 \%)$ & $33(8.4 \%)$ & $5(1.3 \%)$ & 0.098 \\
\hline & Single variant & $\mathrm{N} / \mathrm{A}$ & $6(0.6 \%)$ & $2(0.2 \%)$ & & & & \\
\hline & Combined variant & N/A & $75(6.9 \%)$ & $57(5.2 \%)$ & & & & \\
\hline \multirow{3}{*}{$\begin{array}{l}\text { Anterior CoW } \\
\text { (N) }\end{array}$} & All & $257(47.2 \%)$ & $223(41.0)$ & $64(11.8 \%)$ & $143(73.0 \%)$ & $48(24.5 \%)$ & $5(2.5 \%)$ & $<0.001$ \\
\hline & Complete posterior part & $19(3.5 \%)$ & $198(4.5 \%)$ & $60(11.0 \%)$ & & & & \\
\hline & Posterior part variant & $238(43.8 \%)$ & $25(36.4 \%)$ & $4(0.7 \%)$ & & & & \\
\hline \multirow{3}{*}{$\begin{array}{l}\text { Posterior CoW } \\
(\mathrm{N} \times 2)\end{array}$} & All & $234(21.9 \%)$ & $351(32.2 \%)$ & $503(46.2 \%)$ & $123(31.4 \%)$ & $154(39.3 \%)$ & $115(29.3 \%)$ & $<0.001$ \\
\hline & Complete anterior part & $38(3.5 \%)$ & $182(16.5 \%)$ & $226(20.8 \%)$ & & & & \\
\hline & Anterior part variant & $196(18.0 \%)$ & $169(15.5 \%)$ & $277(25.5 \%)$ & & & & \\
\hline
\end{tabular}

$C o W=$ Circle of Willis; $A C o m A=$ anterior communicating artery; $A l=$ precommunicating segment of the anterior cerebral artery; $P C o m A=$ posterior communicating artery; $P 1=$ precommunicating segment of the posterior cerebral artery; $N / A=$ not applicable

*Comparison between study subjects and controls, pooling hypoplasia and non-visualization versus normal

compromised $\mathrm{CoW}$ and severely compromised CoW groups accounted for $14 \%$ and $33 \%$ of the study group, whereas an opposite trend was found in controls with $28 \%$ and $17 \%$, respectively.

The same difference was encountered with the analysis of each individual segments and the anterior/posterior parts of the CoW confirming a significantly lower rate of hypoplasia or non-visualization $(p \leq 0.008)$ in controls except for the P1 (Table 3).

\section{Discussion}

Our major findings were the significantly higher prevalence of $\mathrm{CoW}$ variants and the association of CoW configuration with brain ischemia in the study group, underlining the importance of recognition of these variants for surgical and endovascular treatment planning.

Based on unselected post-mortem studies, the prevalence of normal CoW ranges from $15 \%$ to $59 \%[3,4,31-34]$. In imaging studies completeness of the entire $\mathrm{CoW}$ was reported in $27 \%-90 \%$ of healthy individuals $[7,22,28,29]$ and $18 \%-$ $55 \%$ in cerebrovascular diseases $[6,21,25]$. The different criteria used to define a normal or incomplete $\mathrm{CoW}$ can account for the variability in these data. The prevalence of a complete CoW was $11 \%$ in controls and even lower in our study group (3.5\%) using a firm definition of completeness (all components $\geq 0.8 \mathrm{~mm}$ ) as a prerequisite for development of collateral flow.

\section{Comparison of patients' CoW variants with autopsy and imaging studies}

The non-visualization of any segment and the hypoplasia of A1 were more frequently reported in cerebrovascular patients as compared to healthy subjects, with some overlap between the two groups, while an opposite trend was demonstrated with respect to AComA and PComA hypoplasia (Table 4).

Comparing our study subjects only with CTA studies on cerebrovascular patients, the prevalence of non-visualized AComA (4\%), A1 (4\%) and the most commonly compromised PcomA (41\%) in our analysis was less frequent (versus 6\%-15\% and $47 \%-66 \%$, respectively).

The fact that CTA does not depend on flow velocity (as opposed to 3D TOF MRA) and the higher spatial resolution achieved by 256-slice CT might have contributed to the lower prevalence of non-visualized AComA, A1 and PComA. 
Table 4 Frequency of non-visualized and hypoplastic individual segments and incomplete and hypoplastic anterior and posterior Circles of Willis in autopsy and imaging studies

\begin{tabular}{|c|c|c|c|c|c|c|}
\hline \multirow[t]{2}{*}{ Segment/circle } & & \multirow{2}{*}{$\begin{array}{l}\text { Autopsy studies } \\
{[4,31-34]}\end{array}$} & \multicolumn{2}{|l|}{ Imaging studies } & \multicolumn{2}{|c|}{ Present Study } \\
\hline & & & Controls & Study group & Controls & Study group \\
\hline \multirow[t]{2}{*}{$\operatorname{ACom} A$} & Non-visualization & $0-3.2 \%$ & $\begin{array}{l}1-19 \% \\
{[7,22,23,28,29]}\end{array}$ & $\begin{array}{l}4-40 \% \\
{[6,7,10,18,20,21,26]}\end{array}$ & $3.9 \%$ & $0.5 \%$ \\
\hline & hypoplasia & $3-32 \%$ & $\begin{array}{l}23 \% \\
{[29]}\end{array}$ & $\begin{array}{l}4-11 \% \\
{[20,24]}\end{array}$ & $28.3 \%$ & $20.4 \%$ \\
\hline \multirow[t]{2}{*}{ A1 } & Non-visualization & $0-0.8 \%$ & $\begin{array}{l}1-7 \% \\
{[7,22,23,28,29]}\end{array}$ & $\begin{array}{l}4-15 \% \\
{[6,7,10,18,20,21,24-26]}\end{array}$ & $4.0 \%$ & $1.0 \%$ \\
\hline & hypoplasia & $1.5-7.5 \%$ & $\begin{array}{l}4-10 \% \\
{[7,28,29]}\end{array}$ & $\begin{array}{l}8-24 \% \\
{[7,10,24,26]}\end{array}$ & $7.4 \%$ & $2.0 \%$ \\
\hline \multirow[t]{2}{*}{ PComA } & Non-visualization & $0-3.5 \%$ & $\begin{array}{l}22-38 \% \\
{[7,9,22,23,28,29]}\end{array}$ & $\begin{array}{l}21-66 \% \\
{[6,7,10,12,18-21,24-27]}\end{array}$ & $41.1 \%$ & $28.0 \%$ \\
\hline & hypoplasia & $23-70 \%$ & $\begin{array}{l}38-41 \% \\
{[7,29]}\end{array}$ & $\begin{array}{l}6-18 \% \\
{[7,20,24]}\end{array}$ & $25.3 \%$ & $30.9 \%$ \\
\hline \multirow[t]{2}{*}{ P1 } & Non-visualization & $0-2.4 \%$ & $\begin{array}{l}0-2 \% \\
{[7,22,23,28,29]}\end{array}$ & $\begin{array}{l}3-10 \% \\
{[6,7,10,20,24,26]}\end{array}$ & $5.4 \%$ & $1.3 \%$ \\
\hline & hypoplasia & $12-23 \%$ & $\begin{array}{l}3-6 \% \\
{[7,28,29]}\end{array}$ & $\begin{array}{l}1-8 \% \\
{[6,7,18,20,24]}\end{array}$ & $7.4 \%$ & $8.4 \%$ \\
\hline \multirow[t]{2}{*}{ Anterior CoW } & incomplete & - & $\begin{array}{l}2-12 \% \\
{[7,8,23,28,29]}\end{array}$ & $\begin{array}{l}12-24 \% \\
{[7,10,12,25]}\end{array}$ & $11.8 \%$ & $2.5 \%$ \\
\hline & hypoplastic & - & $\begin{array}{l}4-10 \% \\
{[7,8,28]}\end{array}$ & $\begin{array}{l}17 \% \\
{[8,12]}\end{array}$ & $41.0 \%$ & $24.5 \%$ \\
\hline \multirow[t]{2}{*}{ Posterior CoW } & incomplete & - & $\begin{array}{l}23-39 \% \\
{[23,28,29]}\end{array}$ & $\begin{array}{l}37-74 \% \\
{[6,8,10,12,21,25]}\end{array}$ & $46.2 \%$ & $29.3 \%$ \\
\hline & hypoplastic & - & $\begin{array}{l}29 \% \\
{[28]}\end{array}$ & $\begin{array}{l}15-40 \% \\
{[8,12]}\end{array}$ & $32.2 \%$ & $39.3 \%$ \\
\hline
\end{tabular}

The numbers in brackets are the references.

$A \operatorname{Com} A=$ anterior communicating artery, $A l=$ precommunicating segment of the anterior cerebral artery, $\operatorname{CoW}=$ Circle of Willis, $P C o m A=$ posterior communicating artery, $P 1=$ precommunicating segment of the posterior cerebral artery

However, a certain percentage of the non-visualized segments in this study could have been hypoplastic vessels below the CTA detection capability, as in autopsy studies absence was found rarely $(0 \%-3.5 \%)$.

Comparing our study group analysis with imaging studies on cerebrovascular patients, we found a higher prevalence of AComA and PcomA hypoplasia (28\% and 25\%, respectively). The higher detection rate of hypoplastic communicant arteries thanks to the higher spatial resolution of the 256-slice CT relative to the 16-40-row scanners or the MRA techniques used by other investigators might partly account for this difference.

Discontinuity of the CoW in patients with symptomatic ICA stenosis was associated with higher risk of TIA and ischemic stroke [1]. Subjects with high-grade ICA stenosis or occlusion with nil or only one ipsilateral collateral vessel (A1, PComA) had a higher likelihood of stroke when compared to patients with two functional ipsilateral collaterals [5]. This is in agreement with the higher prevalence of brain ischemia found in our patients with severely compromised CoW ( $p=0.002$ ). We must acknowledge, however, that CT has low sensitivity in the detection of recent ischemia relative to diffusion-weighted magnetic resonance (MR) imaging but only brain CT was performed for the vast majority of the study group according to institutional protocols with only 11 study subjects having concurrent brain MR imaging and CT.

Most of the previous imaging studies on $\mathrm{CoW}$ variants found higher prevalence of hypoplastic or non-visualized segments in cerebrovascular patients $[5,7-9]$ in accordance with our study. The anterior part of the CoW is generally considered the most important route for collateral flow in severe ICA stenosis [5-7, 18, 35]. Kluytman et al. found that the PComA alone had little compensating capacity in ICA occlusion. Bestpreserved hemodynamics was reported if both the anterior and posterior parts of the $\mathrm{CoW}$ were recruited [35].

The high frequency of compromised circles and the clear difference between the study and control groups strongly suggests that our study subjects have fewer functional segments hindering hemodynamic adaptation. Although the study group and controls were significantly different in terms of five cardiovascular risk factors and coronary artery disease, the multivariate logistic regression analysis showed that ICA stenosis was the only independent predictor of CoW morphology $(p<0.001)$. The higher frequency of ipsilateral A1 hypoplasia/ non-visualization was positively associated to ipsilateral ICA 


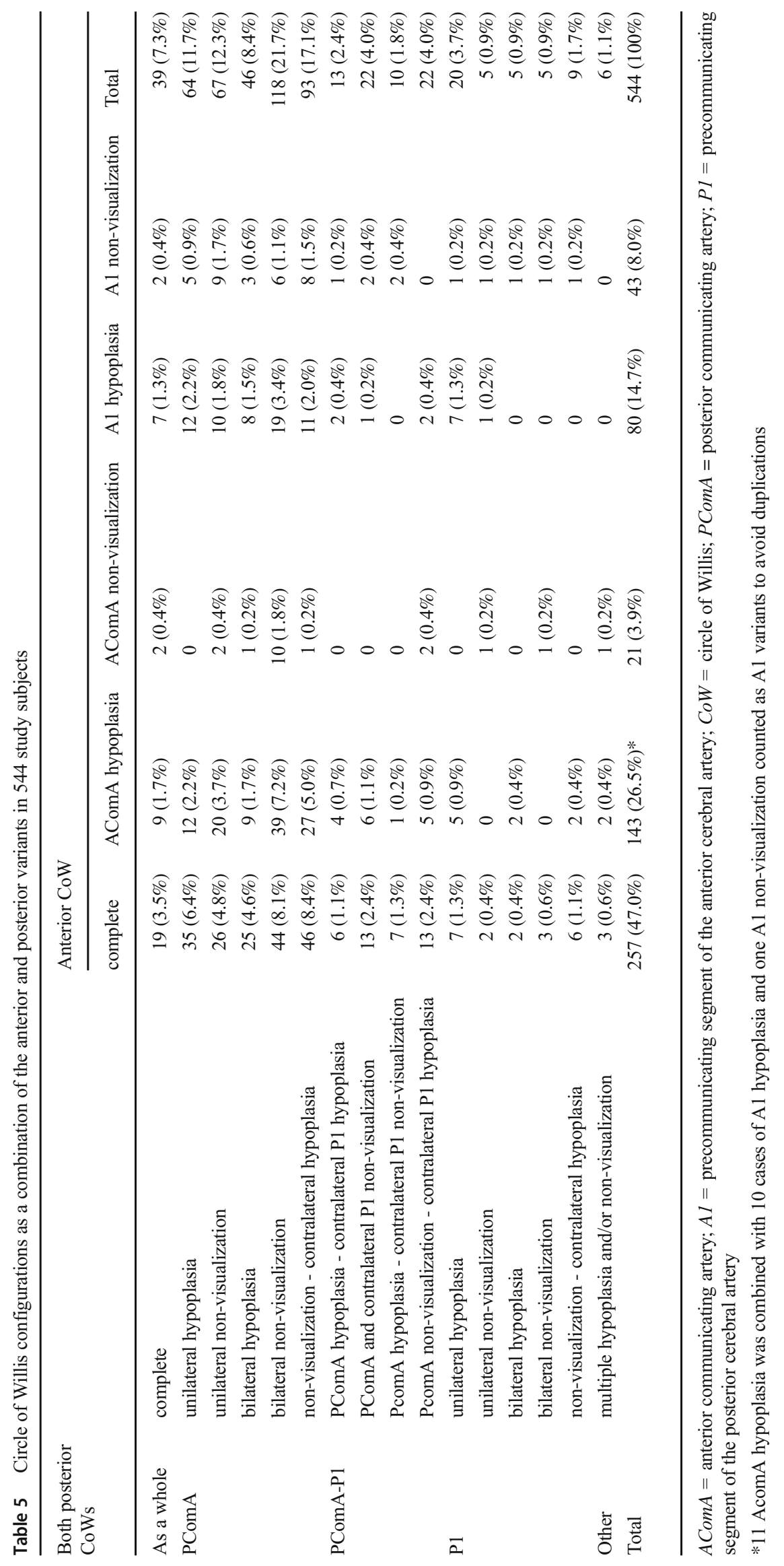




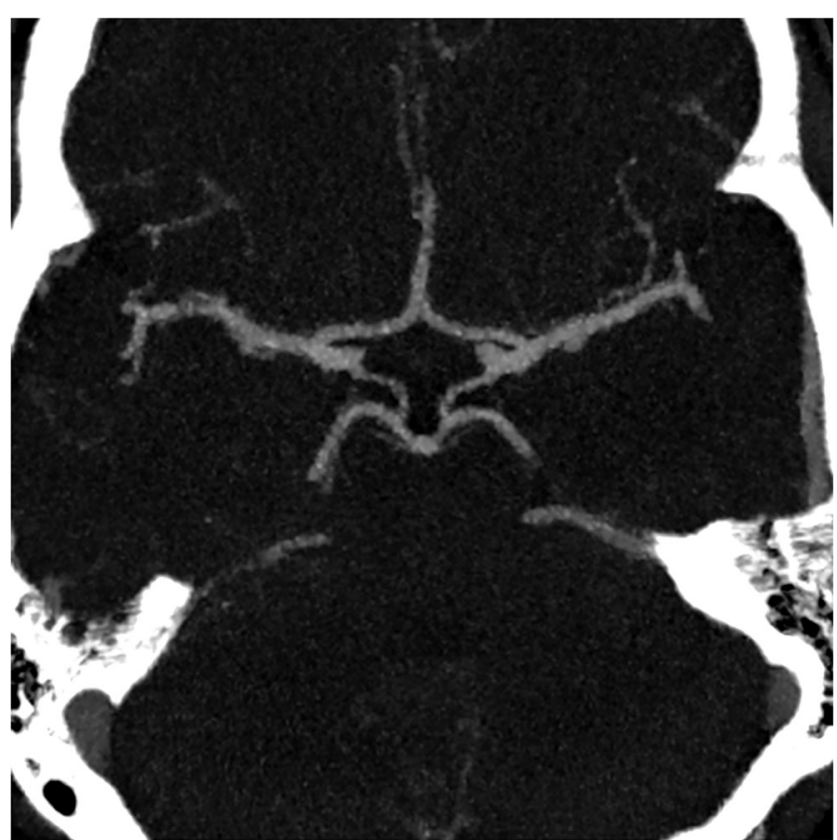

Fig. 1 Thick slab maximum intensity projection $(7 \mathrm{~mm})$ of the Circle of Willis showing a normal circle with all components $\geq 0.8 \mathrm{~mm}$ (group I)

stenosis of $\geq 90 \%(p<0.001)$, also implying a correlation between carotid artery disease and hindered collateral recruitment.

Our research group also found significant association between combined incomplete anterior and ipsilateral posterior parts of the CoW and immediate postoperative neurologic complications after carotid endarterectomy without shunt protection $(31 \%$ vs $5 \%, p<0.001)$ [13]. This is in line with another study, in which $\geq 2$ non-visualized segments versus complete

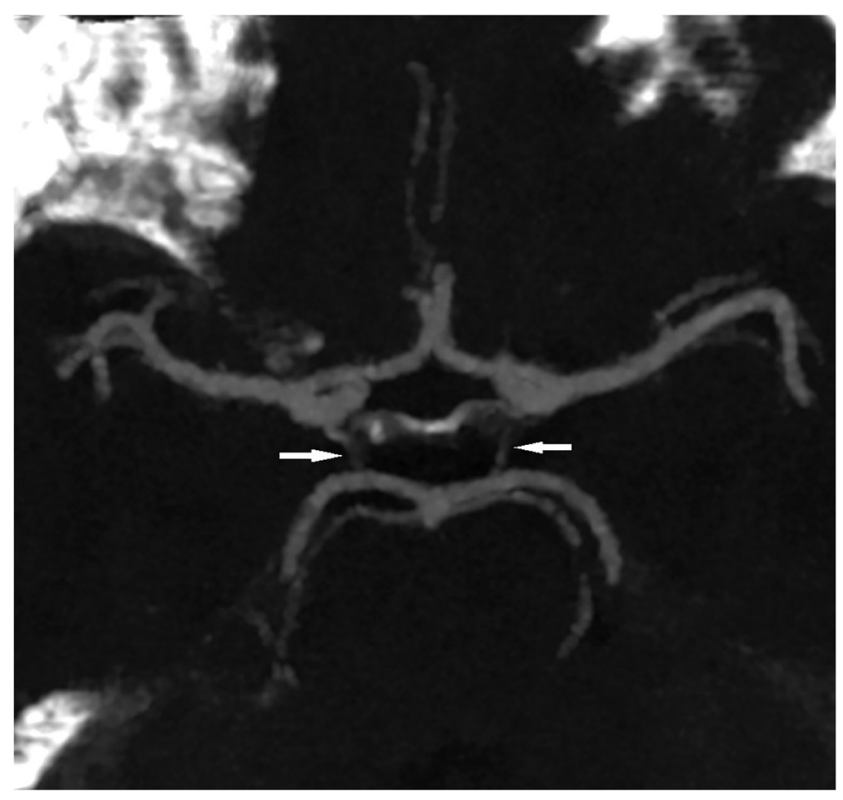

Fig. 2 Thick slab maximum intensity projection $(10 \mathrm{~mm})$ showing bilateral hypoplasia $(<0.8 \mathrm{~mm})$ of the posterior communicating artery (arrows) (group II)

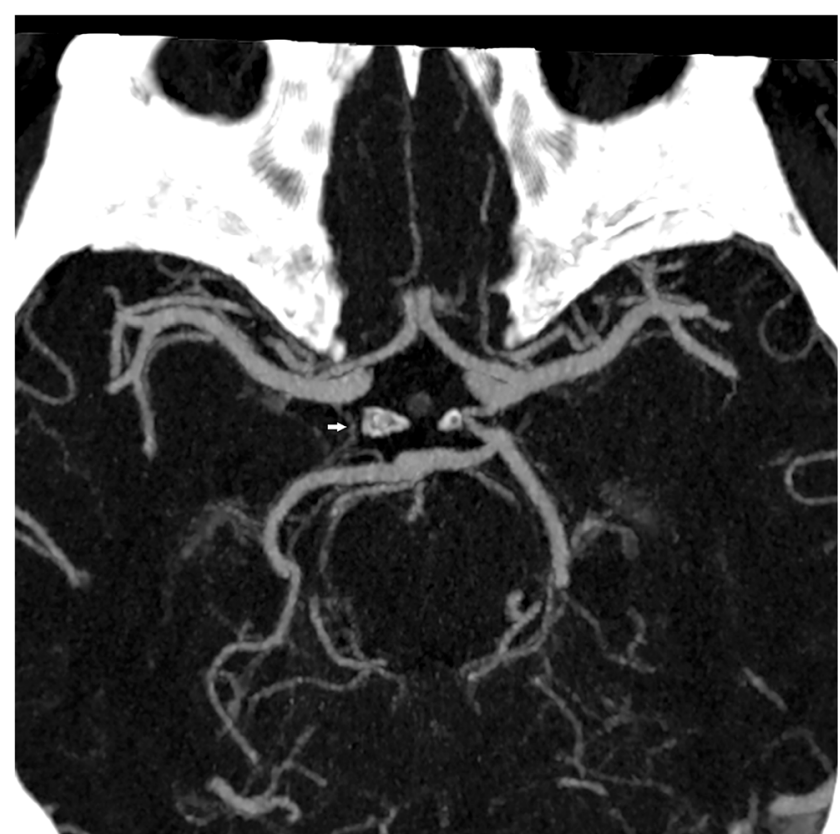

Fig. 3 Thick slab maximum intensity projection $(10 \mathrm{~mm})$ : the right posterior communicating artery is not visualized. The filiform vascular structure filled with contrast along its expected course is the vein of Rosenthal (arrow) (group III)

CoW were shown to have a statistically significant risk to develop carotid clamping intolerance [11]. In another study, in case of contralateral ICA occlusion, the risk of intraoperative TIA was significantly increased when both parts of the CoW (in particular the posterior part) were incomplete [12].

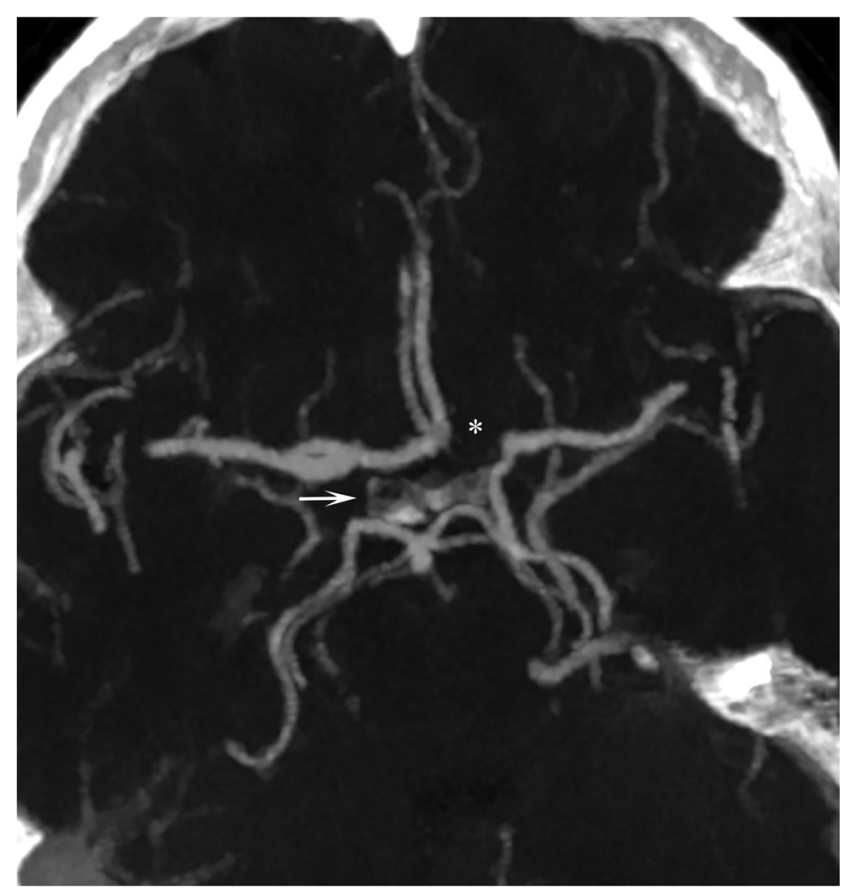

Fig. 4 Thick slab maximum intensity projection $(8 \mathrm{~mm})$ : neither the left precommunicating segment of the anterior cerebral artery (asterics) nor the right posterior communicating artery (arrow) is visualized (group IV) 
Three limitations of our study were the lack of comparison with DSA as reference of standard, the possible bias between the study and control groups and the fact that the study group was limited to patients eligible for carotid endarterectomy with either asymptomatic ICA stenosis or symptomatic stenosis with TIA, amaurosis fugax or minor ischemic stroke. DSA and diffusion-weighted MR imaging are not routinely performed as CTA has taken over the role of DSA in the preoperative assessment of the carotid arteries in our institution, moreover it can be easily performed together with brain CT. Further investigations with a well-matched control group including diffusion-weighted MR imaging are needed.

In conclusion, highly variable CoW morphology compared to controls was demonstrated and a likely compromised CoW in relation to ICA stenosis and brain ischemia was observed in a large cohort of carotid endarterectomy subjects.

Funding The authors state that this work has not received any funding.

\section{Compliance with ethical standards}

Guarantor The scientific guarantor of this publication is Péter Vince Banga, MD.

Conflict of interest The authors of this manuscript declare no relationships with any companies, whose products or services may be related to the subject matter of the article.

Statistics and biometry Giovanni Di Leo, MSc kindly provided statistical advice for this manuscript.

Informed consent Written informed consent was waived by the Institutional Review Board.

Ethical approval Institutional Review Board approval was obtained.

\section{Methodology \\ - retrospective \\ - cross sectional study \\ - performed at one institution}

Open Access This article is distributed under the terms of the Creative Commons Attribution 4.0 International License (http:// creativecommons.org/licenses/by/4.0/), which permits unrestricted use, distribution, and reproduction in any medium, provided you give appropriate credit to the original author(s) and the source, provide a link to the Creative Commons license, and indicate if changes were made.

\section{References}

1. Henderson RD, Eliasziw M, Fox AJ, Rothwell PM, Barnett HJ (2000) Angiographically defined collateral circulation and risk of stroke in patients with severe carotid artery stenosis. North American Symptomatic Carotid Endarterectomy Trial (NASCET) Group. Stroke 31:128-132
2. Barnett HJ, Meldrum HE (2001) Endarterectomy for carotid stenosis: new approaches in patient selection. Cerebrovasc Dis 11(Suppl 1):105-111

3. Alpers BJ, Berry RG (1963) Circle of Willis in cerebral vascular disorders. The anatomical structure. Arch Neurol 8:398-402

4. Battacharji SK, Hutchinson EC, McCall AJ (1967) The Circle of Willis-the incidence of developmental abnormalities in normal and infarcted brains. Brain 90:747-758

5. Hedera P, Bujdakova J, Traubner P, Pancak J (1998) Stroke risk factors and development of collateral flow in carotid occlusive disease. Acta Neurol Scand 98:182-186

6. Hartkamp MJ, van Der Grond J, van Everdingen KJ, Hillen B, Mali WP (1999) Circle of Willis collateral flow investigated by magnetic resonance angiography. Stroke 30:2671-2678

7. Waaijer A, van Leeuwen MS, van der Worp HB, Verhagen HJ, Mali WP, Velthuis BK (2007) Anatomic variations in the circle of Willis in patients with symptomatic carotid artery stenosis assessed with multidetector row CT angiography. Cerebrovasc Dis 23:267-274

8. Kwak HS, Hwang SB, Chung GH, Lee SY (2015) Pattern of circle of Willis between normal subject and patients with carotid atherosclerotic plaque. Neurology Asia 20:7-14

9. Ross MR, Pelc NJ, Enzmann DR (1993) Qualitative Phase-Contrast Mra in the Normal and Abnormal Circle of Willis. AJNR Am J Neuroradiol 14:19-25

10. Pennekamp CWA, van Laar PJ, Hendrikse J et al (2013) Incompleteness of the Circle of Willis is Related to EEG-based Shunting During Carotid Endarterectomy. Eur J Vasc Endovasc Surg 46:631-637

11. Montisci R, Sanfilippo R, Bura R, Branca C, Piga M, Saba L (2013) Status of the Circle of Willis and Intolerance to Carotid Crossclamping During Carotid Endarterectomy. Eur J Vasc Endovasc Surg 45:107-112

12. Lee JH, Choi CG, Kim DK, Kim GE, Lee HK, Suh DC (2004) Relationship between circle of Willis morphology on 3D time-offlight MR angiograms and transient ischemia during vascular clamping of the internal carotid artery during carotid endarterectomy. AJNR Am J Neuroradiol 25:558-564

13. Banga PV, Varga A, Csobay-Novak C et al (2016) Incomplete Circle of Willis Is Associated With a Higher Incidence of Neurologic Events During Carotid Eversion Endarterectomy Without Shunting. J Vasc Surg 63:14s-14s

14. Hendrikse J, Klijn CJM, van Huffelen AC, Kappelle LJ, van der Grond J (2008) Diagnosing cerebral collateral flow patterns: Accuracy of non-invasive testing. Cerebrovasc Dis 25: 430-437

15. Sallustio F, Kern R, Gunther M et al (2008) Assessment of intracranial collateral flow by using dynamic arterial spin labeling MRA and transcranial color-coded duplex ultrasound. Stroke 39:18941897

16. Hendrikse J, van Raamt AF, van der Graaf Y, Mali WPTM, van der Grond J (2005) Distribution of cerebral blood flow in the circle of Willis. Radiology 235:184-189

17. Schomer DF, Marks MP, Steinberg GK et al (1994) The Anatomy of the Posterior Communicating Artery as a Risk Factor for Ischemic Cerebral Infarction. N Eng J Med 330: $1565-1570$

18. Miralles M, Dolz JL, Cotillas J et al (1995) The Role of the Circle of Willis in Carotid Occlusion - Assessment with Phase-Contrast MrAngiography and Transcranial Duplex. Eur J Vasc Endovasc Surg $10: 424-430$

19. Katz DA, Marks MP, Napel SA, Bracci PM, Roberts SL (1995) Circle of Willis - Evaluation with Spiral Ct Angiography, MrAngiography. and Conventional Angiography. Radiology 195: 445-449

20. Stock KW, Wetzel S, Kirsch E, Bongartz G, Steinbrich W, Radue EW (1996) Anatomic evaluation of the circle of Willis: MR 
angiography versus intraarterial digital subtraction angiography. AJNR Am J Neuroradiol 17:1495-1499

21. El-Barhoun EN, Gledhill SR, Pitman AG (2009) Circle of Willis artery diameters on MR angiography: An Australian reference database. J Med Imaging Radiat Oncol 53:248-260

22. Krabbe-Hartkamp MJ, van der Grond J, de Leeuw FE et al (1998) Circle of Willis: Morphologic variation on three-dimensional timeof-flight MR angiograms. Radiology 207:103-111

23. Hoksbergen AWJ, Majoie CBL, Hulsmans FJH, Legemate DA (2003) Assessment of the collateral function of the circle of Willis: Three-dimensional time-of-flight MR angiography compared with transcranial color-coded duplex sonography. AJNR Am J Neuroradiol 24:456-462

24. Han A, Yoon DY, Chang SK et al (2011) Accuracy of CT angiography in the assessment of the circle of Willis: comparison of volume-rendered images and digital subtraction angiography. Acta Radiologica 52:889-893

25. Wholey MWA, Nowak I, Wu WCL (2009) CTA and the Circle of Willis. Early use of multislice CTA to evaluate the distal internal carotid artery and the Circle of Willis and their correlation with stroke. Endovascular Today 7:33-44

26. Velthuis BK, van Leeuwen MS, Witkamp TD, Ramos LMP, van der Sprenkel JWB, Rinkel GJE (2001) Surgical anatomy of the cerebral arteries in patients with subarachnoid hemorrhage: comparison of computerized tomography angiography and digital subtraction angiography. J Neurosurg 95:206-212

27. van der Lugt A, Buter TC, Govaere F, Siepman DAM, Tanghe HLJ, Dippel DWJ (2004) Accuracy of CT angiography in the assessment of a fetal origin of the posterior cerebral artery. European Radiology 14:1627-1633

28. Li Q, Li JL, Lv FJ, Li KW, Luo TY, Xie P (2011) A multidetector CT angiography study of variations in the circle of Willis in a Chinese population. Journal of Clinical Neuroscience 18:379-383

29. Karatas A, Coban G, Cinar C, Oran I, Uz A (2015) Assessment of the Circle of Willis with Cranial Tomography Angiography. Medical Science Monitor 21:2647-2652

30. (1991) North American Symptomatic Carotid Endarterectomy Trial. Methods, patient characteristics, and progress. Stroke 22: 711-720

31. Alpers BJ, Berry RG, Paddison RM (1959) Anatomical studies of the circle of Willis in normal brain. AMA Arch Neurol Psychiatry 81:409-418

32. Riggs HE, Rupp C (1963) Variation in form of circle of Willis. The relation of the variations to collateral circulation: anatomic analysis. Arch Neurol 8:8-14

33. Lazorthes G, Gouaze A, Santini JJ, Salamon G (1979) Arterial Circle of the Brain (Circulus-Arteriosus-Cerebri). Anatomia Clinica 1:241-257

34. Puchades-Orts AN-GM, Ortuno-Pacheco G (1976) Variation in form of circle of Willis: some anatomical and embryological considerations. Anat Rec 185:119-123

35. Kluytmans M, van der Grond J, van Everdingen KJ, Klijn CJM, Kappelle LJ, Viergever MA (1999) Cerebral hemodynamics in relation to patterns of collateral flow. Stroke 30:1432-1439 